\title{
FISIOLOGÍA DE LA ILUSIÓN Y DE LA DÉCADENCE: EL PROBLEMA DEL ACTOR Y DEL TEATRO EN NIETZSCHE Y WAGNER
}

\author{
Giuliano Campioni \\ Universidad de Pisa
}

RESUMEN: El punto de separación fundamental de las estéticas de Nietzsche y Wagner es el problema del comediante y el lugar del teatro en la sociedad y en las artes. Toda la crítica de Nietzsche al ideal estético wagneriano puede sintetizarse en la acusación de «teatrocracia», con todas sus implicaciones psicológicas, sociológicas e incluso políticas. Pero esta oposición puede rastrearse ya en la época schopenhaueriana y wagneriana de Nietzsche, en la que, a pesar de la admiración hacia Wagner, Nietzsche concibe y otorga al actor un papel distinto de lo que hace Wagner, en las artes y, en particular, en la música. El último Nietzsche, con su concepto del Estado dionisíaco, no hará más que radicalizar esta divergencia inicial.

Palabras clave: actor - teatro - decadencia

ABSTRACT: The main point of discord in the aesthetics of Nietzsche and Wagner is the comedian's problem and the role of theatre in society and in the arts. Nietzsche's entire criticism of the Wagnerian aesthetic ideal can be synthesized in the accusation of «theatrocracy», with all its psychological, sociological and even political implications. But this opposition can be traced further back to Nietzsche's Schopenhauerian and Wagnerian period, where, in spite of his admiration of Wagner, Nietzsche conceives of and gives the actor a different role to that given by Wagner, in the arts and, in particular, in music. The later Nietzsche, with his concept of the Dionysian State, simply radicalizes this initial divergence.

Keywords: actor - theatre - decadence

1. INSTINTOS DOMINANTES: LA «VOLUNTAD DE CONOCIMIENTO»DE NIETZSCHE CONTRA LA TEATRALIDAD DE WAGNER

En el prefacio de La genealogía de la moral, Nietzsche caracteriza la «fundamental voluntad de conocimiento» (GM, KSA V 248) como su «instinto dominante». En un fragmento póstumo del invierno de 1887, Nietzsche escribe sobre Wagner: «no se entiende nada de Wagner si no se ve en este instinto [del actor y del teatro] su faculté maîtresse, su instinto dominante» ${ }^{1}$.

1. KSA XIII 136: 11[322]/FP IV 455. Cf. también WA 8, KSA VI 30 y KSA XIII 600. Nietzsche usa la expresión «instinto dominante» (dominierender Instinkt) varias veces al traducir e interpretar la categoría faculté maitresse, central en el pensamiento de Hippolyte Taine. 
En una famosa carta de octubre de 1888 a la señorita Meysenbug, el filósofo define a Wagner como «un genio de la mentira» y a sí mismo como su opuesto: «el genio de la verdad». Y es en el interior de esta oposición radical donde Nietzsche siente, analiza, vivisecciona el caso Wagner, aplicando una violencia sobre esa parte de sí que conserva una inconsolable pena por la amistad perdida:

[...] nada puede compensarme el hecho de haber perdido en los últimos años la simpatía de Wagner. iCuántas veces sueño con él, y siempre en el estilo de nuestras relaciones confidenciales de antaño! Entre nosotros no ha habido nunca una mala palabra, ni siquiera en mis sueños, muchas veces estimulantes y agradables, y con nadie quizá me he reído nunca tanto. Pero ya todo ha terminado: y para qué sirve tener razón en muchos puntos contra él. iComo si de este modo la simpatía perdida pudiese ser borrada de la memoria! Y cosas parecidas ya las he vivido antes, y probablemente las seguiré viviendo. Son los sacrificios más duros que el proceso de mi vida y de mi pensamiento me han exigido (carta a Köselitz de 20 de agosto de 1880).

Por tanto, el significado del alejamiento de Nietzsche no debe buscarse en el plano de las relaciones humanas o "personales»: Humano, demasiado humano señala la fatigosa recuperación (contra la fascinación de la música de Wagner) de una perspectiva radicalmente antimítica y terrenal, con la voluntad de liberarse de caminos prefijados. Los diarios de Cosima ofrecen una documentación de cuánto dolor — hasta la obsesión que renacía en el sueño- le costaba también a Wagner el abandono, la «traición» del joven amigo y cómo la elección de Nietzsche por la limpieza racional y la crítica podía tomar el aspecto, según las palabras de Edouard Schuré 2 , de nibilisme écoeurant, un primado del conocimiento

2. Cf. C. Wagner, Die Tagebücher, ed. de M. Gregor-Dellin y D. Mack, 2 vols., München/ Zürich: Piper, 1976-1977, vol. II (1869-1877), p. 467 (28 de diciembre de 1879): «Ayer noche, [Richard] me había leído algún pasaje del nuevo libro del pobre Nietzsche, y le vino a la mente la definición de Schuré: nihilisme écoeurant». El musicólogo alsaciano Édouard Schuré (1841-1929), defensor de la causa de Wagner, había publicado en 1875 Drame musical, cuyo segundo volumen está dedicado a Wagner; el libro fue traducido al alemán por Hans von Wolzogen (publicado en Leipzig en 1877), y tuvo una segunda edición en francés en 1886, aumentada con un estudio sobre el Parsifal. El escrito de Schuré reelabora, en muchos puntos y a menudo con las mismas imágenes, los temas de El nacimiento de la tragedia, conectándolos estrechamente con las teorías de Wagner (en especial, Ópera y drama). En el primer libro (La Grèce) Schuré cita directamente a Nietzsche a propósito de Apolo y Dioniso como «los dos polos del alma griega» («Esta idea ha sido desarrollada con originalidad y valentía por el notable libro de Nietzsche Die Geburt der Tragödie aus dem Geiste der Musik, Leipzig, 1872. Este libro puede ser considerado, por sus profundas intuiciones, como el que ha iluminado de forma muy nueva el origen y la esencia de la tragedia griega»), y a propósito del juicio sobre las Bacantes de Eurípides (pp. 57 y 58). Schuré dejó su testimonio sobre el "caso Nietzsche» («la enfermedad dominante en las nuevas generaciones») y sobre las sensaciones durante y después del Festival de Bayreuth: «Encontré a Nietzsche en Bayreuth, en 1876, en las primeras representaciones de El anillo del Nibelungo. [...] Hablando con él, me impresionó la superioridad de su espíritu, la extrañeza de su fisonomía. [...] Era al mismo tiempo el ojo de un agudo observador y de un visionario fanático. [...] Ya sufría el comienzo de esa enfermedad cerebral que lo dominaría más tarde, pero más aún sufría una melancolía profunda y callada». Schuré insiste mucho en el sufrimiento visible de Nietzsche, conectándolo con motivos esencialmente psicológicos: en el triunfo artístico y mundano de Wagner, «el autor de El nacimiento de la tragedia desaparecía como todos en la apoteosis del maestro [...] cuando nos marchamos juntos, ninguna crítica, ninguna palabra de crítica se le escapó, pero tenía la misma resignada tristeza de un vencido» (E. Schuré, "L'individualisme et l'anarchie en littérature. F. Nietzsche et sa philosophie»: Revue des deux mondes CXXX [1895], 
histórico que abocaba al escepticismo y al final de toda «veneración». Wagner retomará estos temas, acusando a Nietzsche de aridez «profesoral», y, principalmente, de filisteísmo cultural, en el escrito Público y popularidad, que defiende los superiores derechos del «genio»" ${ }^{3}$, colocándose ya en las antípodas de la con-

774-805). Esta interpretación, predominante en la parte wagneriana, no coincide con la de Rohde en las cartas a su novia: «En cuanto 'hombre famoso', Nietzsche está rodeado de demasiados conocidos y admiradores (admiradoras)»; cf. A. Patzer, «Erwin Rohde in Bayreuth. Sieben ungedruckte Briefe an die Braut»: Nietzsche Studien 20 (1991), 361.

3. Como demuestran los Diarios de Cosima, Wagner trabaja desde el 3 de julio en la tercera parte de su artículo para los Bayreuther Blätter. Con fecha de 21 de julio de 1879 podemos leer: «R. ha trabajado esta mañana en su artículo durante mucho tiempo y con placer, me dice que ataca a Nietzsche, pero sin que nadie, que no esté metido del todo, pueda darse cuenta» (Tagebücher, vol. II, p. 143). Escribe Wagner: «Filólogos y filósofos, sobre todo cuando se hallan en el terreno de la estética, son espoleados e incluso obligados por la física a avanzar sin limitaciones en la crítica de todo lo humano y lo inhumano. Parece, pues, que de los experimentos de esa ciencia extraen la profunda justificación para un escepticismo muy especial, que les permite, alejándose de las opiniones corrientes y volviendo a ellas luego de manera confusa, girar incesantemente sobre sí mismos; y esto parece asegurarles su parte debida en el eterno progreso universal. Cuanto más pasan sin ser observados estos saturnales de la ciencia, mayor es la audacia y la crueldad con la que las víctimas más nobles son despedazadas y arrastradas sobre el altar del escepticismo. [...] Los casos más graves se tienen cuando se tira al mar en general toda grandeza, y en particular, el tan inoportuno 'genio', como algo dañino, más aún, se rechaza el concepto de genio como fundamentalmente falso. Éste es el resultado del más moderno método científico, que generalmente se define como 'escuela histórica' [...]. Hemos señalado los resultados del nuevo método científico, llamado 'histórico', aunque sólo superficialmente (y no puede ser de otro modo para quien no está iniciado en los misterios de la Ilustración): según estos resultados, el sujeto, puramente cognoscente, que se sienta en una cátedra, resulta ser el único ser que tiene derecho a existir. iUna digna aparición como conclusión de la tragedia universal! No es fácil imaginar qué debe llegar a demostrar al final este individuo que conoce, iy no quisiéramos sin duda, al final de su carrera, que tuviese que repetir las exclamaciones de Fausto al comienzo de la tragedia de Goethe! En todo caso, nos tememos que no muchos podrían compartir con él el goce del conocimiento, y pensamos que, para ese gran placer del individuo, admitiendo por lo demás que se dé, el Estado, que se ocupa del interés general, gastaría demasiado dinero. En cuanto a la utilidad general, las cosas irían ya muy mal sólo por el hecho de que es difícil considerar a ese purísimo sujeto cognoscente como un ser humano más. Pasa su vida delante y detrás de la cátedra; no dispone, para el conocimiento de la vida, de un espacio más amplio que lo que le deja este cambio de sitio. El aspecto intuitivo de todo aquello que piensa le es negado, en la mayor parte de los casos, ya desde la primera juventud, y su contacto con la llamada realidad de la existencia es un andar a ciegas sin sentir. Sin duda, nadie le haría mucho caso si no hubiese universidades y cátedras, que nuestro Estado, tan orgulloso de sus intelectuales, se preocupa de mantener con generosidad. Él, con sus semejantes y otros 'filisteos de la cultura', podrá aparecer como un público en el que se mezclan de cuando en cuando, para vaniloquios académicos, retoños de príncipes amantes de la lectura. Al arte, que cada vez más le parece al Goliat del conocimiento sólo un rudimento de un precedente estadio cognoscitivo de la humanidad, más o menos como el cóccix que nos ha quedado de la cola animal, al arte le presta aún atención sólo si le ofrece perspectivas arqueológicas para justificar escolásticas afirmaciones históricas. [...] No se le pasa por la cabeza el dirigirse al pueblo, que por su parte no se preocupa en absoluto de los intelectuales; pero también es difícil decir por qué medio el pueblo debería llegar por fin a ciertos conocimientos. Y sin embargo, sería una tarea no indigna tomar seriamente en consideración este último problema. El pueblo aprende, en efecto, siguiendo caminos totalmente opuestos a quien conoce de manera histórico-científica, es decir, en este sentido no aprende absolutamente nada. Si bien no posee un conocimiento abstracto, el pueblo no obstante conoce: reconoce a sus grandes hombres y ama al genio, que ellos odian; y en fin, algo que a ellos les horroriza, venera lo divino [...]. La crítica histórica [...] está sumergida en el judaísmo y se asombra de que hoy en una mañana de domingo suenen aún las campanas por un hebreo crucificado hace dos mil años, justamente como todo hebreo se asombra de eso" (R. Wagner, Publikum und Popularität, en Gesammelte Schriften und Dichtungen, Lepzig, 1907 ss., vol. X, pp. 81-86). Schuré, en su ensayo, retoma todas estas críticas contra la «rabia iconoclasta»y el «scepticisme écoeurante» de 
cepción juvenil, cuando Wagner, en Una comunicación a mis amigos (1851), afirmaba que en Grecia «no se conocía entonces lo que hoy nosotros llamamos genio: nadie era un genio porque todos lo eran» ${ }^{4}$. De esta acusación de socratismo, de destructor de la veneración y de la ilusión (Wahn) necesaria para la vida, se hace portavoz en una carta a Nietzsche la fiel wagneriana Mathilde Maier:

Nos hemos construido con esfuerzo y paciencia una religión sin Dios, para salvar al menos - si también Dios está perdido - lo divino, y ahora usted nos quita el fundamento que, por muy aéreo y nebuloso que sea, es sin embargo aún lo suficientemente fuerte para mantener el mundo: iel mundo de todo lo que nos es querido y sagrado! — la metafísica es sólo una ilusión [Wahn], ¿̇pero qué es la vida sin ilusión? [...] Con la caída del mundo metafísico, la vida terrenal sola adquiere un poder tiránico. [...] iY ahora disuelva todo! Todo fluctuante - ya ninguna imagen sólida- isólo movimiento eterno! (julio de 1878).

Mathilde Maier retomaba con fuerza las posiciones que Nietzsche había expresado en el período wagneriano: la necesidad de la ilusión metafísica y la reivindicación de las fuerzas antihistóricas y suprahistóricas contra la posición nihilista del discípulo de Heráclito, incapaz de actuar, una vez que estaba condenado a ver por todas partes un devenir, un flujo de fuerzas: «Un hombre tal ya no creería en su mismo ser, ya no creería en sí mismo, vería fluir una tras otra las cosas y en puntos móviles y se perdería en este río del devenir [...] casi no se atrevería ya a levantar el dedo» (HL, KSA I 250).

En su respuesta a Maier (15 de julio de 1878), Nietzsche expresa abiertamente el alejamiento irreversible de aquel Wagner que pretendía «elevar» y redimir y que en cambio era sobre todo enfermedad («ese oscurecimiento metafísico de todo lo que es verdadero y simple, la lucha con la razón, más aún, contra la razón, esta lucha que en cada cosa quiere ver un milagro y algo monstruoso»), y emerge el sentido de la liberación como acabado amor hacia las cosas próximas, fin de la «enfermedad del ideal» y elección de los horizontes abiertos. Desde hace tiempo el filósofo se daba cuenta de la imposibilidad de permanecer en la ilusión (Wahn) sabiendo que es tal: el mito pierde toda eficacia activa y el riesgo es el letargo, la inacción, la pasividad. Cuando Nietzsche llegará a conocer, indirectamente por Gast, la expresión usada por Schuré en el círculo wagneriano contra él, le molestará dolorosamente: «Necesito salud de todas las clases — algo ha penetrado demasiado al fondo de mi corazón, este 'nihilismo desalentador'!» (a H. Köselitz, 13 de marzo de 1881). Pero comentando este asunto, en el otoño de 1881, encontramos usado por Nietzsche, por primera vez, el término: «En qué medida todo horizonte intelectual más claro parece un nihilismo» (12[57]).

Ya en 1878, también por parte de Wagner y de su círculo, el alejamiento de Nietzsche es entendido sólo en conexión con la enfermedad, el «caso» Nietzsche entendido como caso clínico, psicológico, patológico. Así Wagner escribe a Overbeck el 24 de mayo de 1878:

Nietzsche: «En lugar de Dioniso, símbolo de la inspiración y del éxtasis, pone a Sócrates» (E. Schuré, "L'individualisme et l'anarchie en littérature...", cit.).

4. R. Wagner, Eine Mitteilung an meine Freunde, en Dichtungen und Schriften, ed. de D. Borchmeyer, 10 vols., Frankfurt a. M.: Insel, 1983 (en adelante: DuS), vol. VI, p. 219. 
Ciertamente han ocurrido en él cambios llamativos: pero quien lo ha observado desde hace algunos años en sus tormentos psíquicos, no ha podido hacer otra cosa más que constatar que en él se ha verificado desde hace tiempo una catástrofe temida y de manera no del todo inesperada.

Y paralelamente, además de en las páginas de los Diarios de Cosima, podemos encontrar más testimonios epistolares del duro juicio dominante en Bayreuth. Véase por ejemplo la carta de Cosima a Marie von Schleinitz:

El libro de Nietzsche no lo he leído. Me ha bastado hojearlo y leer algunas frases significativas para ponerlo ad acta. En el autor se ha cumplido un proceso que desde hace tiempo veía avanzar y contra el cual he combatido con mis pocas fuerzas. iMuchas son las cosas que han contribuido al nacimiento de este triste libro! Al final se ha sumado también Israel, en la figura de un doctor Rée muy escurridizo, muy frío, en apariencia tomado y sometido por Nietzsche; en realidad, en cambio, es él quien lo domina con el engaño; a pequeña escala la relación entre judaísmo y germanismo [...]. Malwida niega decididamente el influjo negativo del doctor Rée, que a ella le gusta tanto... Me ruega también que no abandone a Nietzsche, pero para cada frase que he leído tengo un comentario, y sé que aquí ha vencido el mal [...]. El mismo Wagner sostiene sobre Nietzsche que de este bulbo debería haber nacido una flor. El bulbo se atrofió, realmente una cosa repugnante (KGW IV/4 46-47).

Este juicio extremo permanecerá como una constante en la literatura wagneriana: hasta las vulgaridades presentes en las cartas de Cosima, convertida ya en un Fafner de memorias, y sacerdotisa, en clave empresarial, del templo de Bayreuth. A la muerte del filósofo, Cosima vuelve a recorrer la historia de la relación explicando su «traición» en términos tranquilizadores:

Hay que enfocar el caso bajo el aspecto físico sólo y exclusivamente: por muy triste que sea, al menos preserva del horror en que caeríamos al ver a un hombre renegar de lo que ha amado y de donde ha sacado su auténtica relevancia ${ }^{5}$.

Y este juicio se repite varias veces también para justificar un significativo testimonio del período de Tribschen:

Un día vino a verme y me dijo, con palabras violentamente agitadas, que tenía la sensación de que todo aquello en lo que en ese momento estaba moviéndose era falso; a lo que yo le respondí: gracias a Dios usted es un helenista y siga siéndolo, nuestra amistad no se verá disminuida en absoluto por ello y podrá recorrer un camino seguro ${ }^{6}$.

Esta precoz sensación de incomodidad de Nietzsche, frente a una acabada teatralización de la existencia —su «índole» constitucionalmente antiteatral— remite al sentido general de la confrontación con el músico-histrión: es la centralidad de esta dimensión que atraviesa los escritos de Nietzsche a partir de los

5. C. Wagner, Das zweite Leben. Briefe und Aufzeichnungen. 1883-1930, ed. de D. Mack, München, 1980, p. 549 (carta a M. von Meysenbug, 8 de octubre de 1900).

6. Ibid., p. 552 (carta a Seidl, 14 de noviembre de 1900). 
fragmentos inmediatamente sucesivos a El nacimiento de la tragedia, donde es justamente la noción de teatrocracia aplicada a Wagner lo que muestra las primeras fisuras de la adhesión, hasta la neta formulación de los últimos años, cuando Wagner representa precisamente "el advenimiento del comediante en la música» (WA $\int 11$, KSA VI 37).

Ya en los apuntes de 1874, dedicados al músico, «Wagner es un actor frustrado» (32[8], FP I 537): «quería hacer también lo que le impactaba. De sus modelos no comprendía más que lo que él podía imitar. Naturaleza de actor» (32[10], FP I 537).

Como actor quería imitar al hombre sólo en su aspecto más real y efectivo: en el supremo afecto. Pues su naturaleza extremista vio en todos los otros estados debilidades y falsedad. Hay peligro extraordinario para el artista al describir las pasiones. Lo embriagador, lo sensual, lo extático, lo inmediato, la conmoción a toda costa - itendencias terribles! (32[16], FP I 539).

La renovación del arte y una reforma social que pase a través de la «teatrocracia» debe tener en cuenta sobre todo una "masa muy tosca, y volver a dominar la teatrocracia se ha demostrado hasta ahora como algo imposible [...]. Aquí radica la importancia de Wagner: aspirar a la tiranía con la ayuda de las masas teatrales» (32[61], FP I 548). «Es un discurso popular, que se deja pensar sin una enorme simplificación incluso de lo más noble. Tiene que actuar a gran distancia y tiene que cimentar el caos popular» (32[22], FP I 540).

También el amor de Thomas Mann por Wagner ha tenido que enfrentarse a la fuerza de esta connotación: Wagner «el comediante», el gran Cagliostro. En Mario y el mago el tema de la "posesión hipnótica», del dominio mediante la despersonalización, la unidad de la voluntad en el obedecer y el mandar, son calcos conscientes de las formulaciones nietzscheanas. (También en otros sitios, por ejemplo en el Felix Krull, con el tema de la ilusión escénica y la realidad degradada que está detrás de la máscara del actor — la visita al camerino descubre el elemento horripilante-, Mann muestra tener en cuenta muchas de las páginas de Nietzsche y Wagner sobre este tema.)

El Wagner actor se convierte incluso, para Nietzsche, en los últimos años en la clave para comprender la situación de la época, el «histrionismo» en una categoría básica de comprensión. La decadencia es pérdida de centro y fragmentación de la personalidad en una exasperada, caótica fluidez de los roles sociales, que se revelan como rápidamente intercambiables e impiden todo proyecto social:

El hombre sólo adquiere sentido y valor en la medida en que es una piedra de un gran edificio: para tal fin, ante todo, debe ser sólido, debe ser «piedra»... sobre todo no - icomediante! [...]. Todos nosotros ya no somos material para una sociedad (FW \$356).

\section{GENIO MÍMICO Y ARTE TRÁGICO}

Se malentiende la crítica a Wagner del último Nietzsche si no se capta en ella su carácter de despiadada autocrítica, de puntillosa inversión de los presupuestos 
metafísicos de la fase de El nacimiento de la tragedia. Las primeras formulaciones de Nietzsche sobre el tema del actor debemos leerlas dentro de esta plena consonancia con el proyecto wagneriano. En El drama musical griego, por ejemplo, la actividad del actor es reconducida al clima de las fiestas populares de las procesiones dionisíacas, y a las danzas medievales de San Juan y San Vito. El motivo central no es la voluntad de suscitar en los otros la ilusión, sino la disolución de la persona en la plenitud de vida del éxtasis dionisíaco. En términos wagnerianos, la despersonalización como núcleo del genio mímico es vista como la naturaleza del estar fuera de sí: «Entramos en otro ser, comportándonos como individuos transformados por una magia [...] el terreno vacila, decae la fe en la indisolubilidad y la rigidez del individuo»(GMD, KSA I 522). Y sin embargo, en los escritos juveniles de Nietzsche, el tema no tiene el mismo peso que en Wagner, el cual hace del mimo-actor en la escena el médium de la perfecta comunicación dramática (milagro sensible en el espacio y el tiempo). «El artista del futuro» será para Wagner «indudablemente el poeta. ¿Y quién será el poeta? Indudablemente el actor. ¿Y quién será el actor? Necesariamente la unión de todos los artistas» ${ }^{7}$. La ilusión de las artes plásticas se convierte en el drama, en la acción concreta del mimo, en «verdad». La obra de arte del futuro atribuye a la pérdida de contacto con los actores la desaparición del poeta dramático, que «loco de orgullo quiso elevarse por encima de sus compañeros y, privado del afecto y del entusiasmo de ellos, se retiró tras su cátedra de literato y por sí solo quiso dictar el drama a esos mismos que lo habían creado de un plumazo para su libre instinto de representación ${ }^{8}$.

El proyecto nietzscheano en esta fase, más que las teorías estéticas juveniles de Wagner, muy influidas por Feuerbach, sigue al Wagner de Beethoven. Aquí, mediante las estructuras metafísicas de la filosofía schopenhaueriana, el primado de la comunicación a través del cuerpo cede su puesto a la centralidad de la música que suscita una comunicación magnética. En Nietzsche, por tanto, la misma disolución del individuo no se dirige tanto a la afirmación del hombre «genérico» (que siempre se da en la determinación espacio-temporal), sino que significa sobre todo destrucción de una apariencia fenoménica vinculada al tiempo y al espacio (el principium individuationis de Schopenhauer). Todo el proyecto de $E l$ nacimiento de la tragedia busca la refundación de una cultura orgánica asentada sobre bases estéticas y confiada a la potencia de la magia onírica y visionaria suscitada por el genio musical, según las tesis del Beethoven de Wagner. De todos modos, el carácter afirmativo de lo dionisíaco en Nietzsche muestra la fidelidad de ese concepto a las formulaciones de Ópera y drama y esto remitiendo al espíritu popular-caballeresco de las fiestas dionisíacas y con la fuerte presencia del tema del cuerpo. Si lo dionisíaco de Nietzsche se centra en el tema del Beethoven de la magia autónoma de la música — la omnipotencia de la música reside en su inmediata identificación con la Voluntad única y originaria-, sin embargo no ha olvidado el sentimiento pánico indicado por Wagner:

7. R. Wagner, Das Kunstwerk der Zukunft (1849), DuS, vol. VI, p. 139. Para un análisis puntual e inteligente del tema cf. F. Manno, «Fantasmagoria e creazione nell'arte scenica: attore e mimo in Wagner e Nietzsche», en M. C. Fornari (ed.), La trama del testo. Su alcune letture di Nietzsche, Lecce: Micella, pp. 123-151.

8. Ibid., p. 83 . 
Cuando el que está poseído por una profunda excitación, se dirige desde su estado de ánimo interior a la naturaleza circundante, encuentra en ella un alimento que rejuvenece o un impulso que modifica su estado moral. Él atribuye a aquello que lo domina o lo rejuvenece de tal modo un gran poder, en la misma medida en que él mismo se encuentra en un estado de ánimo supremamente excitado. La relación en la que él sabe que se encuentra con la naturaleza, la siente involuntariamente expresada en una gran conexión que los fenómenos naturales tienen con él y con su estado de ánimo... En esta gran acción recíproca que él siente, los fenómenos naturales se condensan frente a su sentimiento, de una manera precisa, a la que le añade una sensación individual análoga a la impresión que produce en él, y a su propio estado de ánimo, y finalmente le añade también unos órganos que — adecuados a su entendimiento- sirven para expresar esta sensación. Entonces él habla con la naturaleza y ella le responde $e^{9}$.

En una acentuación dionisíaca, este planteamiento caracterizó incluso la recuperación de la plena dimensión dionisíaca en el último Nietzsche, en particular algunas páginas de Ecce homo. Hay que observar, además, dentro de una primera consonancia general, una diferencia en el papel que Nietzsche atribuye al actor-mimo respecto a Wagner, una ulterior diferencia en el aspecto resaltado. Comparemos, por ejemplo, el escrito Actores y cantantes con las formulaciones de La visión dionisíaca del mundo. En Wagner la «demoníaca» tendencia a la despersonalización sólo es salvada de que se transmute en juego por la intervención de la «serenidad» del texto poético:

La serenidad de la que hablamos es también el feliz elemento que retiene al mimo realmente dotado de caer en el abismo hacia el que se siente empujado por la sobrehumana tendencia a la despersonalización del ejercicio de su arte. Quien es capaz de imaginarse a sí mismo al borde del abismo, verá con horror que aquí se trata de un juego con la propia personalidad, que, en un momento dado, puede amenazar con trasformarse en verdadera locura; y aquí precisamente se introduce la conciencia del juego ${ }^{10}$.

El actor, el mimo, se identifica completamente con la expresión del fondo vital, es su inmediata transparencia, por lo que la «veracidad» es «el fundamento del arte del mimo» ${ }^{11}$. En Nietzsche, el actor se diferencia del hombre dionisíaco «natural», sólo es su representación. En el juego con la embriaguez dionisíaca, el actor se descarga de la embriaguez de la que en cambio está poseído el actor wagneriano, asimilable más bien al hombre «loco» del cortejo de Dioniso. El juego tiene pues una función protectora respecto al fondo trágico: lo descubre y evita su efecto letárgico-nihilista. El actor de Nietzsche se sitúa por tanto en esos mecanismos de representación que el mismo Uno-originario produce por sí mismo, para descargar la tensión contenida, que en caso contrario sería insoportable, de alegría y dolor. El actor es para Nietzsche de todos modos un instrumento, un topo ciego: sólo como tal es valorizado para la realización de la «sublime ilusión» (de significado metafísico), hecha posible por el efecto mágico de la música, que reduce la fuerza de la apariencia a símbolo. Hacia el gremio

9. R. Wagner, Oper und Drama, DuS, vol. VII, pp. 213 ss.

10. R. Wagner, Über Schauspieler und Sänger, DuS, vol. IX, p. 251.

11. Ibid., p. 254. 
de los actores, por lo demás, Nietzsche siente la desconfianza y el prejuicio corrientes:

Es triste, pero característico de la indescriptiblemente pobre sociabilidad alemana, que sólo encuentres diversión relacionándote con actores. A mí también me ha pasado eso. La aureola del arte libre ilumina también a sus servidores más indignos. Por lo demás, idealizamos ese estrato de la sociedad (CO II, carta 61, a Deussen, febrero de 1870).

Era ya una crítica evidente al planteamiento de Wagner, por su valorización «de estos hijos perdidos de nuestra sociedad moderna, que veía merodear como gitanos en medio del caos de un nuevo ordenamiento del mundo» ${ }^{12}$.

\section{LA FISIOLOGÍA DEL ACTOR Y LAS MÁQUINAS DE LA ILUSIÓN}

Describiendo el tema central de la metafísica de artista —ya en 1870-1871—, Nietzsche subrayaba la necesidad de descubrir su proceso fisiológico:

La voluntad como dolor supremo produce desde sí misma un éxtasis, que se identifica con la intuición pura [Anschauen] y con la producción de la obra de arte. ¿Cuál es el proceso fisiológico? ¿En qué lugar debe producirse una ausencia de dolor? - ¿pero cómo? Aquí se produce la representación como medio para ese éxtasis supremo. El mundo es, sin embargo, ambas cosas al mismo tiempo, como núcleo de la única Voluntad terrible, como representación es el mundo difuso de la representación, del éxtasis. La música demuestra que todo aquel mundo, en su pluralidad, ya no se siente como disonancia (KSA VII 166: 7[117]/FP I 166).

Y, por tanto, no por casualidad el tema del actor es retomado en función antiwagneriana en la gran fase de alejamiento a partir de Humano, demasiado bumano, con el análisis de los mecanismos genéticos y fisiológicos que están en la base del «milagro» de la obra de arte, en la presunta inmediatez del estado onírico, que satisface el deseo. Si ahora para Nietzsche la tarea wagneriana es la de mostrar las máquinas y el trabajo que mantienen la ilusión de una «milagrosa instantaneidad del nacimiento», un medio será sin duda el análisis del arte de la representación:

Ahora en la obra del artista nadie puede ver cómo ha surgido; ésta es su ventaja, porque dondequiera que se puede ver el devenir, uno se enfría bastante. La obra de arte acabada de la representación rechaza todo pensamiento sobre el devenir; ella tiraniza como perfección presente. Por ello los artistas de la representación son considerados geniales por excelencia y no lo son, en cambio, los hombres de ciencia. En verdad, esa estima y esta infravaloración son sólo una puerilidad de la razón (MA I $\$ 162$ ).

El actor se presenta ahora como figura de la fisiología de la representación, el momento central del aparato ilusorio (máquinas de escena, fondos, luces, etc.) y el alejamiento respecto a la pretensión wagneriana es neto. Esta última es definida como procedimiento metafísico:

12. R. Wagner, Epilogischer Bericht... (1871), DuS, vol. III, p. 338. 
Pertenece a las características del filosofar metafísico, el exasperar un problema y ponerlo como insoluble a menos que no se considere como solución un milagro, por ejemplo ver la esencia del actor en la auto-alienación y en una auténtica metamorfosis; cuando, en cambio, el verdadero problema es con qué medios de ilusión el actor consigue suscitar la impresión de metamorfosis (KSA VIII 449: 23[449]).

Esta reutilización de La paradoja del actor de Diderot seguirá siendo una constante en el discurso de Nietzsche, hasta la afirmación de Talma usada precisamente contra Wagner:

Se es comediante por el hecho de tener la ventaja de una sola cognición que el resto de los humanos no tiene: lo que debe producir efecto no puede ser verdadero. Este principio es formulado por Talma: contiene la entera psicología del comediante; y contiene también — sin la menor sombra de duda- su moral ${ }^{13}$.

Ya en Aurora, por lo demás, Nietzsche usa contra Wagner, a propósito del actor, la expresión «mono ideal»: el actor, aunque sea virtuoso y genial, no puede evitar quedarse en la superficie: es la indagación genealógica e histórico-científica lo que puede hacer presente el espesor de una condición o de un personaje.

indudablemente sería un bonito descubrimiento que bastase sólo el actor clarividente, en lugar de los pensadores, de los eruditos, de los especialistas todos, para iluminar en sus profundidades la esencia de cualquier condición! No obstante, no deberíamos olvidar, en cuanto se hacen oír esas pretensiones, que el actor es precisamente un mono ideal y mono hasta tal punto que no puede creer en absoluto en la «esencia» o en lo «esencial»: para él todo es juego, sonido, gesto, escena, escenario y público (M $\$ 324$, «Fisiología de los actores»).

Wagner había usado la expresión «mono ideal» en una dirección muy distinta en Arte y política alemana (1867): para su lucha contra la civilización francesa y latina, enemiga de su nuevo arte, "puramente humano", es decir, germánica. Su enfoque, ligado principalmente a la reforma teatral, aborrecía y estigmatizaba moralmente —usando a Voltaire contra Voltaire - al pueblo francés como una «mezcolanza de monos y tigres» ${ }^{14}$, carente de cualquier idealismo, cuya vida

13. WA, KSA VI 31. François-Joseph Talma, uno de los más grandes trágicos del teatro francés, contribuyó a la renovación del teatro dramático. Gozó de la amistad y la estima de Napoleón. En sus Mémoires, Talma habla de su transición desde una primera fase de representación ligada a la inmediatez y a la identificación, al estudio de la técnica de la respiración y al control completo de la representación (F.-J. Talma, Mémoires de J.-F. Talma écrites par lui-même et recueillis et mis en ordre sur les papiers de sa famille par Alexandre Dumas, Paris, 1850, vol. II, p. 28). En sus reflexiones se advierte un fuerte influjo de Diderot: "Me doy cuenta de mi recitación mientras estoy recitando" (L.-F.-H. Audibert, «Entretiens avec Talma», en Mélanges de littérature et d'histoire, Paris, 1839, p. 234). Cf. también C. Mellinet, «Une conversation avec Talma à Nantes en 1813»: Revue du Breton I (1835), 98: «Un actor no se olvida nunca de que es tal en la escena: es siempre comediante, en caso contrario sería un mal comediante». Sobre la relación entre Talma y Diderot cf. P. Bastier, «À propos du Paradoxe: Talma plagiaire de Diderot»: Revue d'Histoire Littéraire de la France 11 (1904), 108 ss., y A. Freer, «Talma and Diderot's Paradox on Acting»: Diderot Studies 8 (1966). Sobre Talma véase el volumen M. di Fazio, François Joseph Talma. Primo divo. Teatro e storia fra Rivoluzione, Impero e Restaurazione, Milano: Electa, 1999. Cf. también B. Villien, Talma. L’acteur favori de Napoléon, Paris: Pygmalion, 2001.

14. R. Wagner, Deutsche Kunst und deutsche Politik, DuS, vol. VIII, p. 293. 
es esencialmente convención teatral y artificio. Para Wagner, la teatralidad del poder y de la corte se hace ejemplar y transforma la vida entera «en sentido teatral», donde el teatro vital, el del «pueblo», pierde toda dignidad y valor para convertirse en una expresión de virtuosismo mecánico. Arte y política alemana valoriza al actor (artista) que reproduce y crea, contra el mimo que se limita a imitar (el idealismo contra el realismo), y pone en el centro la comparación del mono (el francés) y del hombre (el alemán). La repugnancia del hombre hacia el mono nace, no tanto de la diferencia, como de la semejanza exterior entre el virtuosismo mecánico, artificial, de la imitación (que caracteriza al teatro francés), y la reproducción ideal de la realidad (propia de las artes plásticas y de la poesía que deben marcar al teatro alemán). "La corte de Versalles había sido construida para producir un efecto teatral» ${ }^{15}$.

Wagner exaspera temas presentes en la tradición cultural alemana, que veía la cultura francesa como continuación y empeoramiento de la época de Luis XIV, en la que la forma y la convención mataban la vida. El teatro de Voltaire era la expresión más significativa de esa cultura, sobre él había escrito Herder: «Nunca he encontrado en él ningún grito inarticulado de la naturaleza y de la pasión que fuesen naturales» ${ }^{16}$. La ausencia de «naturaleza» se convierte en lugar común de Lessing a Schiller: Wagner es heredero de esta tradición ${ }^{17}$. En Francia, la vida está pues absorbida —y, por así decirlo, agotada - por las formas de la cultura: es esencialmente convención y uniformidad impuesta desde arriba, expresión de una Zivilisation mecánica. En Oper und Drama, Wagner afirma que el lenguaje ha perdido progresivamente su capacidad de comunicar «sentimentalmente», es decir, de manera auténtica y verdadera, porque ha perdido, de manera irremediable, el nexo con las propias raíces originarias e inconscientes: la lengua ya sólo obedece a la lógica y a la convención que se imponen a través de la represión del sentimiento natural. «Nuestra lengua descansa en una convención religiosa, política e histórica, la cual, bajo el dominio de la convención personificada, bajo Luis XIV, fue establecida en Francia muy lógicamente por una academia por orden del soberano, e impuesta como una regla» ${ }^{18}$. De aquí un lenguaje que ha perdido el elemento poético — es decir, conjuntivo_, para pasar a afirmar la

15. Ibid., p. 295.

16. J. G. Herder, Journal meiner Reise im Jahr 1769 I, en Sämtliche Werke, ed. Suphan, Berlin, 1877-1913, vol. IV, p. 481.

17. En qué medida esto era un lugar común, lo demuestra la manera en que es asimilado por el joven Nietzsche, que en 1864, aún estudiante en Pforta, escribe una composición poética de corte académico, con ocasión del tercer centenario del nacimiento de Shakespeare. En una estilización romántica, la poesía representa la tumba abandonada y desolada del poeta inglés. Nietzsche retoma elementos de la tradición polémica contra el teatro francés, que había hecho olvidar a Shakespeare: «la gente es demasiado austera. El arte huye — / y en Francia se hace fútil y lujosa / [...] En la escena el héroe, que manos y pies / movía cuidadosamente, / tal como prescribía la etiqueta de la Corte. / Nunca acalorarse, sino con esta calma dignidad / en fríos versos exteriorizar el sentimiento». El renacimiento es confiado al poder taumatúrgico del famoso actor inglés, considerado el recuperador del teatro shakespeariano: «Es un Garrick quien con sus triunfos / doma a la masa obtusa, y desde lo profundo / del corazón resucita el mundo de Shakespeare, / perdido ya en el sueño del pueblo». El joven estudiante de Pforta recuerda, además, a Lessing y Herder, «los nobles ingenios» de la tradición alemana, que apreciaron al poeta inglés como capaz de traer, en un respiro retórico, «un nuevo sol matutino» (KGW I 3).

18. R. Wagner, Oper und Drama, DuS, vol. VII, pp. 225-226. 
lógica, es decir, el elemento que busca «analizar» $\mathrm{y}$ «descomponer». Esta lengua caracteriza a los pueblos neolatinos, incapaces, por tanto, de expresarse sentimentalmente, también en el arte, que es convencional y frío.

Para Nietzsche, ya muy lejos de compartir las ideas wagnerianas, en el actor está presente únicamente el juego escénico de la apariencia del sentimiento, sin ningún interés por la génesis y las causas reales de éste. En las investigaciones genealógicas de Humano, demasiado humano —apoyadas por una reflexión etnológica-, el fenómeno mímico-gestual es puesto como fundamento de la música en cuanto expresión directa del corazón del mundo. La música absoluta es presentada ahora como el residuo histórico de un complejo conjunto de intenciones simbólicas, radicadas, en el origen, en la imitación mediante gestos, vista como el inicio de la comunicación. La «música absoluta» se presenta de esta manera como la memoria condensada de un rico patrimonio de gestos y movimientos imitativos, con lo que se daba, en un origen no metafísico, sino histórico, la comunicación de los afectos. La música absoluta llega de todos modos siempre al final de un proceso: no es música originaria.

En cuanto fue posible la comprensión por gestos, pudo nacer además un simbolismo del gesto: quiero decir, fue posible el entendimiento sobre un lenguaje de signos, de manera que en primer lugar se produjeron sonido y gesto (al cual el primero se añadía de manera simbólica), y más tarde sólo el sonido. Parece ser que en las épocas pasadas se producía ya a menudo el mismo fenómeno que hoy ocurre ante nuestros ojos y oídos en el desarrollo de la música, especialmente de la música dramática: mientras en un primer momento, la música sin danza y mimo (lenguaje de gestos) que la expliquen es un vacío ruido, el oído a través de una larga habituación a esa unión entre música y movimiento, es educado a interpretar inmediatamente figuras musicales y alcanza al fin un grado de rápida comprensión en el que ya no necesita para nada el movimiento visible para comprender al músico. Se habla entonces de música absoluta, es decir, de música en la que todo es

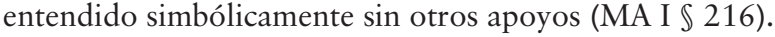

Justamente en estas afirmaciones está el fundamento del último discurso de Nietzsche sobre el histrión dionisíaco, como veremos. Contra el teatro burgués de la moda y del lujo, que había llevado al actor al virtuosismo maquinal (la búsqueda del efecto) y a la degradación servil, Wagner hallaba el fundamento del arte de despersonalización del instinto mímico en la genuinidad de la expresión popular no corrompida por el dominio de la civilización, e invitaba a buscar modelos del arte escénico más bien en las figuras del «bufón», del teatro de marionetas, en los escenarios de las ferias: «El hombre natural no deformado lo vemos ya sólo en las formas más materiales de la vida, más aún, en la vida de las esferas más bajas» ${ }^{19}$. Wagner cuenta en Actores y cantantes su encuentro revelador con el verdadero y «taumatúrgico» genio popular, representado por un actor de marionetas en la plaza de una feria: una genuinidad instintiva que se contrapone al dominio de la máscara de la convención y del rol, que marca la vida de la odiada Francia. Este tema polémico atraviesa el escrito Arte y política alemana. Balzac, siempre muy leído y admirado por Wagner (como confirman

19. R. Wagner, Schauspieler und Sänger, DuS, vol. IX, p. 209. 
los Diarios de $\operatorname{Cosima}^{20}$ ), ha sabido revelar, con una fidelidad realista que le deja a uno en una "completa desolación", el reverso de la teatralidad que escondía, bajo velos atractivos y seductores, el horror de la civilización.

Nietzsche retoma el tema de la conexión entre actor y origen bajo popular disolviendo completamente el aura de populismo romántico. El origen del instinto comunicativo no reside en una incorrupta cohesión comunitaria, sino justamente en las formas de vida suscitadas por la disolución de la comunidad en las restricciones y en la lucha por la vida. El «placer de la imitación», base del mimo-actor, se ha desarrollado como instinto:

[...] con la máxima facilidad en las familias del pueblo bajo, que bajo las vicisitudes de la opresión y de la constricción tuvieron que pasar su vida en una extrema dependencia, que tuvieron que bandearse dócilmente, organizarse una y otra vez en relación con nuevas circunstancias, adaptarse a actitudes siempre nuevas, distintas, adquiriendo poco a poco la capacidad de ondear a todo tipo de viento, y de esta manera casi transformándose en el mismo viento; convirtiéndose en los maestros de ese arte, hecho de carne y sangre, del eterno jugar a esconderse, que en los animales se llama mimicry, hasta que al final toda esta habilidad, aumentada de generación en generación, se hace despótica, irracional, irrefrenable, y aprende, en cuanto instinto, a mandar sobre los otros instintos y genera al comediante, al «artista» (principalmente el bufón, el cuenta cuentos, el juglar, el payaso, pero también el servidor clásico, el Gil Blas: en estos tipos se tiene, en efecto, la prehistoria del artista y bastante a menudo incluso la del genio) ( $\mathrm{FW} \$ 361)$.

Una vez más, la investigación de Nietzsche establece el instinto, no como un primum, sino como el resultado y la combinación de hábitos históricos y de experiencias repetidas: el genio es un resultado, no un milagro, una acumulación de energía y organización de esta energía. También el arte de Shakespeare, hacia el que en este período Nietzsche muestra poco aprecio, es interpretado como el fruto de un hábito que se ha consolidado en una «segunda naturaleza», creando la especificidad del genio dramático: la habilidad de inventar toda observación sólo en correspondencia al carácter de una persona dada, en relación con una situación: el autor dramático se ha acostumbrado a una especie de discurso hipotético, es decir, teniendo en cuenta el personaje en cuyos labios se pone la frase, hasta convertir este hábito en una "segunda naturaleza» como instinto (KSA VIII 456: 23[146]). Y esto además en directa polémica con Wagner, que había insistido en el momento central de la improvisación en el arte del mimo y había visto en el drama shakesperiano una «improvisación mímica, de sumo valor poético, fijada por escrito» ${ }^{21}$.

La simplificación de la complejidad de lo real, propia del arte dramático - ligada a una embriaguez letárgica, narcótica - tiene en sí misma un efecto de dominio que ve justamente en el actor-tirano la figura central. En $R$. Wagner en Bayreuth, extrema tentativa de empujar a Wagner hacia los griegos, hacia la afirmación trágica, Nietzsche sigue queriendo ver en la simplificación wagneriana la fuerza de concentrar en un único punto focal experiencias heterogéneas, una

20. Cf., por ejemplo, la nota del 7 de diciembre de 1878 en la que Cosima habla del «grandioso pesimismo» de Balzac (Die Tagebücher, vol. II, p. 252).

21. R. Wagner, Über die Bestimmung der Oper, DuS, vol. IX, p. 169. 
condensación del pasado en vista del futuro (Wagner como anti-Alejandro) y en el arte el descanso restaurador antes de la primera batalla, de la confrontación agonal con la compleja realidad. La naturaleza del actor se sitúa en el trasfondo, para eclipsar los potenciales peligros del planteamiento wagneriano.

Sin embargo, ya en los fragmentos de 1874 Nietzsche había emprendido el trabajo de desmitificación; caída la unidad visionaria de música y drama, la unidad de la obra de arte total es vista ahora como sumisión de expresiones artísticas irreducibles a la violencia legisladora de una naturaleza de «actor», que luego desemboca en una teatrocracia. La conjunción que los fragmentos establecen entre «simplificación» y tiranía muestra cómo Nietzsche utiliza connotaciones burckhardtianas de "cesarismo» (los césares modernos como terribles simplificateurs) y de tirano del Renacimiento, para definir el afirmarse de Wagner como potencia. La referencia a Burckhardt está demostrada también por la atribución a Wagner de algunos caracteres típicos del «cesarismo» y la tiranía. Ante todo la ausencia de tradición y la búsqueda de legitimación, unida a la incapacidad de crear una continuidad dinástica: pero sobre todo el concepto de teatrocracia, utilizado contra Wagner, con su aspecto de tosquedad y simplificación en el suscitar los sentimientos inmediatos de las masas, repite el esquema de derivación del tirano cesáreo de la «democracia».

Wagner intenta la renovación del arte desde la única base todavía existente, desde el teatro: aquí realmente se estimula todavía a una masa y no se enseña nada como en los museos y en los conciertos. En realidad es una masa muy tosca, volver a dominar la teatrocracia se ha demostrado hasta ahora como algo imposible. [...] Aquí radica la importancia de Wagner: aspira a la tiranía con la ayuda de las masas teatrales (KSA VII 774: 32[61]/FP I 548).

\section{Y otra vez:}

Wagner valora la simplicidad de la construcción dramática, porque ella es la que actúa con más fuerza. Reúne todos los elementos eficaces, en una época que a causa de su torpeza necesita medios muy rudos y fuertes. Lo lujoso, lo embriagador, lo desconcertante, lo grandioso, lo terrible, lo ruidoso, lo feo, lo extático, lo nervioso, todo es legítimo. Dimensiones enormes, medios enormes. / Lo irregular, los excesos en la ornamentación y en la pompa dan la impresión de riqueza y suntuosidad (KSA VII 774: 32[57]/FP I 547).

Como actor quería imitar al hombre sólo en su aspecto más real y efectivo: en el supremo afecto. Pues su naturaleza extremista vio en todos los otros estados debilidades y falsedad. Hay un peligro extraordinario para el artista al describir las pasiones. Lo embriagador, lo sensual, lo extático, lo inmediato, la conmoción a toda costa - itendencias terribles! (KSA VII 760: 32[17]/FP I 539).

En un breve fragmento del invierno de 1879-1880, la distancia respecto a las posiciones de Wagner será del todo marcada: «iUna nueva cultura no es cosa de actores!»(KSA IX 13: 1[29]). Pero es en los fragmentos de 1874 donde se encuentra la premisa de la sucesiva crítica al teatro como embriaguez opiácea, exaltación fuerte, con estimulantes artificiales, de hombres reducidos a «mulos cansados a los que la vida demasiado a menudo ha aplicado el látigo» (FW $\mathbb{S} 86$ ). 
Una vez más Nietzsche vuelve contra Wagner la crítica que en sus escritos juveniles el músico había dirigido contra el teatro del lujo y de la moda, como estimulante artificial, voluntario atontamiento, evasión de la realidad en cuanto efecto fuerte sin causa eficiente. Nietzsche, en La gaya ciencia, reafirma esta tesis: quien no está agotado, el fuerte, no necesita una «bebida embriagadora»:

En cambio, con una especie de náusea dirige la mirada a estos medios y a quien los utiliza, esos que deben generar un efecto sin causa eficiente - iun remedo de los flujos excelsos del alma! ¿Cómo? ¿Se le regalan alas al topo y soberbias quimeras, antes de que se vaya a dormir, antes de que se arrastre a su cubil? ¿Se le manda al teatro y ante sus ojos ciegos y cansados se ponen grandes lentes? (FW $\mathbb{S} 86$ ).

Pero hay más: Nietzsche utiliza el procedimiento schopenhaueriano del extrañamiento, por el que el «ojo teatral» (M $\mathbb{5} 509)$ del genio está destinado a la escena de la vida para mantener una posición de alejamiento crítico, de no implicación. Aquí está la fidelidad al Schopenhauer «volteriano», muy lejos de todo «histrionismo de la renuncia», la fidelidad de la disección analítica contra el Schopenhauer de la «metafísica», que con todo su «misterioso aparato» habría fascinado también a un «Cagliostro» (FW $\mathbb{S} 99$ ). También el teatro es sometido al «ojo teatral»:

Quien tiene en sí mismo suficiente tragedia y comedia, prefiere mantenerse alejado del teatro: o bien, excepcionalmente, todo el desarrollo escénico - teatro, público y autor incluidos— se le convierte en un auténtico espectáculo trágico-cómico, de manera que, en comparación, la obra representada sólo tiene para él un escaso significado (FW $\mathbb{S} 86)$.

\section{EL CAGLIOSTRO DEMAGÓGICO Y EL «HISTRIÓN» DIONISÍACO}

Pero la teatralidad, el histrionismo, se convierten cada vez más, para Nietzsche, en categorías amplias: el ideal metafísico, todo ideal embriagador, puede tener continuidad de desarrollo y apariencia de unidad sólo en la teatralidad de la «representación», en su «ponerse en escena». Por esto también los filósofos, los moralistas, han sido hasta ahora unos comediantes y es por esta exigencia teatral por lo que el mago Wagner se convierte, en sus últimos años, «ya en un sacerdote, una especie de portador del en sí de las cosas, un 'ventrílocuo' de Dios» (GM, KSA V 346). El dominio y la tiranía aplicados a los débiles necesitan tanto la fuerza de expresión, de la tinta sobrecargada con la que se violenta los nervios enfermos, como la seducción que nace de la ambigüedad y de la indeterminación.

En lo ilógico, en lo semi-ilógico, hay mucha seducción —lo ha adivinado perfectamente Wagner- especialmente para los alemanes, quienes consideran la oscuridad «profundidad». [...] Una especie de ambigüedad, incluso en el fraseo rítmico, es uno de los artificios preferidos; una especie de embriaguez y vagabundeo soñador, que ya no sabe «deducir» y desencadena una peligrosa voluntad de seguir y ceder ciegamente (KSA XI 674: 41[2]).

$\mathrm{Al}$ «cenagal de Bayreuth» («presunción, falta de claridad, ignorancia y mal gusto, todo mezclado»), que impone a Wagner la actitud de "viejo, sumo sacerdote, que nada teme más que los conceptos claros y distintos» (KSA XI 254: 
26[394]), Nietzsche le contrapone una vez más la fuerza analítica de la «psicología» de Stendhal: «il faut être sec, clair, sans illusion».

El Cagliostro demagógico necesita mantener y agitar el estado de disgregación y el caos que lo ha suscitado; lejos de la potencia del "gran estilo", sólo puede fingir ideológicamente la totalidad, cerrar y sublimar la decadencia en la fantasmagoría teatral: esto significa sobre todo anestesiar el sentido de vacío de una realidad fallida, a través de la embriaguez opiácea del drama musical. La posición de Wagner no es una libre elección, es un destino, una necesidad de su fisiología de decadente.

Sabía hasta demasiado bien lo que pierde el artista cuando ante sí mismo pierde la libertad, el respeto. Está condenado a ser un actor. Su arte mismo se le convierte en una tentativa continua de evasión, en un medio para olvidarse, para aturdirse - eso altera, eso acaba por determinar el carácter de su arte. Semejante persona «no-libre» tiene necesidad de un mundo de hachís, de vapores extraños, pesados, envolventes, de toda especie de exotismo y de simbolismo del ideal, sólo para poder liberarse siquiera una vez de $s u$ propia realidad (KSA XIII 601: 23[2]/FP IV 752).

En el último período, remitiéndose continuamente a los «psicólogos» y a las investigaciones contemporáneas francesas, profundiza el análisis fisiológico de la decadencia en su conexión con la disgregación de lo moderno, con la «gran ciudad», hasta ver en la «falsedad inconsciente» un resultado de la lucha de los instintos que aspiran al dominio y que, para ser aprobados y «liberados», se presentan bajo la máscara de valores reconocidos.

El hecho de que el hombre vea lo que impulsa y su «expresión» («la máscara») como dos cosas separadas es un signo de que el instinto está quebrado - un signo de contradicción consigo mismo, y algo mucho menos victorioso. La absoluta inocencia en el gesto, en la palabra, en el afecto, la «buena conciencia» en la falsedad, la seguridad con la que se recurre a las palabras y a las actitudes más grandes y más espléndidas - todo eso es necesario para la victoria (KSA XII 324: 8[1]/FP IV 227).

El artista de la decadencia no deriva su comunicación y expresión de la plenitud de la fuerza vital, del desahogo de energías que se expresa en juegos de formas y ritmos, en la alegría de la destrucción y la recomposición, sino que hace reemerger zonas atávicas de existencia con sus estilos de comunicación y de expresión, a través de la disgregación de la personalidad en la edad moderna: «Cuando el agotado se presenta con el ademán de la máxima actividad y energía: cuando la degeneración provoca un exceso de descarga espiritual o nerviosa, entonces se lo ha confundido con el rico» (KSA XIII 252: 14[68]/FP IV 529).

En la extrema excitación emotiva y en la reactividad constreñida, que Nietzsche asimila a la histeria, el hombre dionisíaco «no deja de observar ningún signo emotivo, posee en máximo grado el instinto de comprender y adivinar, así como en el más alto grado el arte de la comunicación. Se introduce en cada piel, en cada movimiento del alma: se trasforma constantemente» (GD $\mathbb{S} 10$, KSA VI 118). El artista moderno, por su conexión con el agotamiento, está emparentado con las otras formas de degeneración que suscita la gran ciudad: 
La creciente civilización, que también lleva consigo simultánea y necesariamente el aumento de los elementos mórbidos, de lo neurótico-psiquiátrico y de lo criminal...

[...] una especie intermedia surge, el artista, separado de la criminalidad de la acción por debilidad de la voluntad y pusilanimidad social, asimismo todavía no maduro para el manicomio, pero que se introduce lleno de curiosidad con sus dos antenas en ambas esferas ${ }^{22}$.

Contra el histrionismo de la decadencia, hecho posible gracias al agotamiento y al «empobrecimiento de la máquina», muy próximo en su psicología al histerismo, Nietzsche pone como clave del arte afirmativo el histrionismo dionisíaco, como fenómeno de plenitud comunicativa que pasa principalmente a través de la corporeidad, y del que la música, que a partir de Humano, demasiado humano ha perdido todo estatuto de originariedad, es sólo un residuo. «El fenómeno más pleno es siempre el inicio: nuestras facultades de seres humanos culturales han sido sustraídas a facultades más plenas» (KSA XIII 297: 14[119]/FP IV 557). La alucinación de gestos del histrión Wagner no es más que la mimesis, suscitada por la disgregación de la personalidad, de la originaria y plena comunicación dionisíaca, que tiene en su cuerpo su medium y que está en la raíz de todo arte de la afirmación:

El estado estético tiene una superabundancia de medios de comunicación, juntamente con una extrema receptividad a los estímulos y a los signos. Es la cima de la comunicatividad y de la traducibilidad entre seres vivos [...]. No nos comunicamos nunca pensamientos, nos comunicamos movimientos, signos mímicos que nosotros hacemos retroceder para leerlos con pensamientos (KSA XIII 296: $14[119] /$ FP IV 557).

En la recuperación nietzscheana de una totalidad dionisíaca se puede ver una valorización de las temáticas juveniles de Wagner. La dirección del segundo Wagner —en el campo teórico y de filosofía de la música- hacia la «música absoluta», que va acompañada por la valorización de ideales ascéticos, comporta una creciente represión del elemento corpóreo. Nietzsche permanece fiel, en muchos aspectos, al Wagner juvenil, que en La obra de arte del futuro escribía: «Entre todos los géneros de arte, la danza es el más material. Su materia artística es el cuerpo humano, el hombre físico y no una parte de él, sino él todo entero, como se ofrece a la vista, desde los pies a la cabeza ${ }^{23}$. El último Nietzsche vuelve a ser, por tanto, el discípulo de Dioniso, valorizando el histrionismo dionisíaco como expresión de plenitud de vida y perfecta comunicación. La fisiología del trágico recupera plenamente, contra la decadencia y sus máscaras, el valor del arte como estímulo de vida, expresión de potencia. Pero la riqueza de la forma, la misma potencia simbólica del cuerpo, si bien suponen una recuperación de la «comunicación perfecta» del Wagner de Ópera y drama, se diferencian de ella en cuanto que no son inmediatas, sino fruto de una lenta conquista a través de la acumulación de energías. En Ecce homo, el cuerpo es un teatro mágico del

22. KSA XIII 366 ss.: 14[182]/FP IV 599. Cf. también KSA XIII 356: 14[170] y KSA XIII 517: $16[89]$.

23. R. Wagner, Das Kunstwerk der Zukunft, DuS, vol. VI, p. 40. 
universo porque está atravesado por signos que concentran las dispersas energías: «El genio está condicionado por el aire seco, por el cielo puro, y esto quiere decir metabolismo rápido, posibilidad de atraer siempre grandes y también enormes cantidades de fuerza». La extrema sensibilidad fisiológica es acumulación de fuerzas, un estado de «vigor animal», que significa libertad y expresa una potenciación última de la voluntad (estado dionisíaco-divino), en el que ya no existe la casualidad, todo es plenitud y fuerza comunicativa (EH, KSA VI 282).

«Richard Wagner ha sido el hombre con gran diferencia más afín a mí» (EH, KSA VI 268): ésta es la sorprendente afirmación de Ecce homo, donde el histrión dionisíaco se pone en escena contra el histrión de la decadencia, y esto por última vez, antes de la disolución, que aún llevará consigo la trágica mimesis de la plenitud.

Es un prejuicio que yo sea un ser humano. Pero ya he vivido a menudo entre los hombres y conozco todo lo que los hombres pueden experimentar, desde lo más bajo hasta lo más alto. He sido entre los hindúes Buda, en Grecia Dioniso, - Alejandro y César son mis encarnaciones, lo mismo que el poeta de Shakespeare, lord Bakon. Finalmente he sido también Voltaire y Napoleón, quizás también Richard Wagner... Pero esta vez llego como el Dioniso victorioso, que hará de la tierra un día de fiesta...

Y otra vez, el mismo día: «Me dicen que un cierto divino payaso ha terminado en estos días los Ditirambos de Dioniso» ${ }^{24}$.

[Traducción de Marco Parmeggiani Universidad de Málaga]

24. Tarjetas a Cosima Wagner, 3 de enero de 1889. 